\title{
Erratum to: The impact of co-infections on fish: a review
}

\author{
Mohamed H. Kotob ${ }^{1,2}$, Simon Menanteau-Ledouble , Gokhlesh Kumar ${ }^{1}$, Mahmoud Abdelzaher² \\ and Mansour El-Matbouli ${ }^{1 *}$ (D)
}

\section{Erratum to: Vet Res (2016) 47:98 DOI 10.1186/s13567-016-0383-4}

Following publication of this article [1], an error was brought to our attention in the below paragraph.

In Chile, high mortalities were reported in Atlantic salmon farms following co-infection by Caligus rogercresseyi and Neoparamoeba perurans, the causative agent of amoebic gill disease (AGD). C. rogercresseyi was shown to play a vital role in the transmission of $N$. perurans resulting in several outbreaks [52]. Similarly, Lepeophtheirus salmonis, another salmon louse similar to C. rogercresseyi was also found to play a similar role as a vector in the transmission of $N$. perurans and influenced the epizootiology of the disease in Atlantic salmon and increased mortalities in Atlantic salmon farms in the USA [53].

The correct version should be read as follows:

"In Chile, the first outbreak of amoebic gill disease (a condition caused by Neoparamoeba perurans) in Atlantic salmon occurred in fish heavily infected with the sea louse Caligus rogercresseyi [52]. This suggested that C. rogercresseyi might have contributed to the outbreak. Alternatively, it is also possible that both parasites took advantage of a third factor, for example the poor overall health of the fish or the unusually high salinity of the water at the time of the outbreak as both parasites are known to thrive under such high salinity conditions [52].

DNA from $N$. perurans was identified in samples of the sea louse Lepeophtheirus salmonis from a location in the Puget Sound with a prior history of AGD [53]. This suggested that $L$. salmonis harboured the amoeba, possibly on its carapace and that it might play a role in its dispersion.

Interestingly, despite sea lice's absence from Tasmania, AGD is a recurring problem in this region which signifies that the copepod is not essential for AGD outbreak [53]."

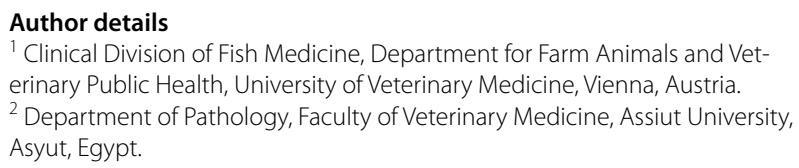

The online version of the original article can be found under doi:10.1186/s13567-016-0383-4.

\section{Publisher's Note}

Springer Nature remains neutral with regard to jurisdictional claims in published maps and institutional affiliations.

Received: 16 March 2017 Accepted: 11 April 2017

Published online: 19 April 2017

\section{Reference \\ 1. Kotob MH, Menanteau-Ledouble S, Kumar G, Abdelzaher M, El-Matbouli M (2016) The impact of co-infections on fish: a review. Vet Res 47:98. doi:10.1186/s13567-016-0383-4}

\footnotetext{
*Correspondence: Mansour.El-Matbouli@vetmeduni.ac.at

${ }^{1}$ Clinical Division of Fish Medicine, Department for Farm Animals and Veterinary Public Health, University of Veterinary Medicine, Vienna, Austria

Full list of author information is available at the end of the article
} 